\title{
Acaricidal efficacy of a new combination of fipronil and permethrin against Ixodes ricinus and Rhipicephalus sanguineus ticks
}

Pascal Dumont ${ }^{*}$, Theodore S Chester ${ }^{2}$, Boyd Gale $^{3}$, Mark Soll$^{2}$, Josephus J Fourie ${ }^{4}$ and Frédéric Beugnet ${ }^{1}$

\begin{abstract}
Background: Two blinded, controlled laboratory studies were conducted to assess the acaricidal efficacy of a new combination of fipronil and permethrin (Frontline Tri-Act ${ }^{\oplus} /$ Frontect ${ }^{\oplus}$ ) against two tick species. Study A evaluated the efficacy of the product against both Ixodes ricinus and Rhipicephalus sanguineus and Study B evaluated the efficacy against $R$. sanguineus only.
\end{abstract}

Methods: 16 (Study A) and 12 (Study B) healthy adult dogs were allocated to two groups in each study. Dogs in Group 1 served as untreated controls. Dogs in Group 2 were treated with a new topical spot-on formulation containing 6.76\% $(\mathrm{w} / \mathrm{v})$ fipronil $+50.48 \%(\mathrm{w} / \mathrm{v})$ permethrin once on Day 0 . Each dog of study A was infested with 50 unfed adult ticks of each species and each dog of study B was infested with 50 unfed adult Rhipicephalus sanguineus prior to treatment (Day -2 in Study A, Day -1 in Study B) and post treatment on Days 7, 14, 21 and 28. The ticks were removed and counted $48 \mathrm{~h}$ after treatment (Day 2) or subsequent infestations (Days 9, 16, 23 and 30). Acaricidal efficacy was defined as the percent reduction in the number of live ticks in the treated group compared to the untreated control group.

Results: The percent efficacy in the treated group for $R$. sanguineus was 100\%, 100\%, 100\%, 100\% and 96.7\% in Study A, and $94.4 \%, 100 \%, 100 \%, 98.7 \%$ and 98.0\% in Study B, for counts performed on Days 2, 9, 16, 23 and 30, respectively. For I. ricinus, in Study A, the percent efficacy of the treatment was 100\%, 100\%, 100\%, 100\% and $99.2 \%$ for counts performed on Days 2, 9, 16, 23 and 30, respectively. There was a significant difference of the geometric mean numbers of live ticks between the treated and control groups at each time point in each study ( $p=0.005$ for every day in Study A, and $p<0.005$ for every day in Study B).

Conclusions: A single topical administration of a combination of fipronil and permethrin provides excellent acaricidal efficacy against both I. ricinus and R. sanguineus for at least 4 weeks.

Keywords: Ticks, Ixodes ricinus, Ripicephalus sanguineus, Permethrin, Fipronil, Dog, Acaricide, Frontline Tri-Act ${ }^{\circledast / F r o n t e c t}{ }^{\oplus}$

\section{Abrégé}

Contexte: Deux études expérimentales contrôlées et randomisées ont été conduites afin de mesurer l'efficacité acaricide d'une nouvelle combinaison de fipronil et de perméthrine (Frontline Tri-Act ${ }^{\circledast / F r o n t e c t}{ }^{\oplus}$ ) contre deux espèces de tiques. L'étude A a évalué l'efficacité du produit vis-à-vis de Ixodes ricinus et Rhipicephalus sanguineus et l'étude B a évalué l'efficacité vis-à-vis de $R$. sanguineus seul.

(Continued on next page)

\footnotetext{
* Correspondence: pascal.dumont@merial.com

'Merial S.A.S., 29 Av. Tony Garnier, 69007 Lyon, France

Full list of author information is available at the end of the article
} 
(Continued from previous page)

Méthodes: Pour chaque étude, 16 (étude A) et 12 (étude B) chiens adultes en bonne santé ont été répartis en deux groupes. Les chiens du groupe 1 servaient de témoins non traités. Les chiens du groupe 2 étaient traités une fois au jour 0 avec une nouvelle formulation spot-on topique contenant 6,76\% (w/v) de fipronil + 50,48\% (w/v) de perméthrine. Chaque chien de l'étude A a été infesté par 50 tiques adultes à jeun de chaque espèce et chaque chien de l'étude $B$ a été infesté par 50 Rhipicephalus sanguineus adultes à jeun, avant le traitement (jour -2 dans l'étude A, jour -1 dans l'étude B) et après traitement, aux jours 7, 14, 21 et 28. Les tiques ont été retirées et comptées 48 h après traitement (jour 2) ou après chaque infestation (jours 9, 16, 23 et 30). L'efficacité acaricide est définie comme le pourcentage de réduction du nombre de tiques vivantes dans le groupe traité par rapport au groupe témoin non traité.

Résultats: Le pourcentage d'efficacité contre R. sanguineus dans le groupe traité a été de 100\%, 100\%, 100\%, 100\% et $96,7 \%$ dans l'étude $A$, et 94,4\%, 100\%, 100\%, 98,7\% et 98,0\% dans l'étude B, pour les comptages réalisés aux jours 2, 9, 16, 23 et 30, respectivement. Pour I. ricinus, dans l'étude A, le pourcentage d'efficacité du traitement était de 100\%, 100\%, 100\%, 100\% et 99,2\% pour les comptages réalisés aux jours 2, 9, 16, 23 et 30, respectivement. Une différence significative entre les moyennes géométriques de tiques vivantes entre les groupes traité et témoin, a été retrouvée à chaque point de comptage dans les deux études ( $p=0,005$ pour chaque jour dans l'étude $A$, et $\mathrm{p}<0,005$ pour chaque jour dans l'étude B).

Conclusions: Une administration topique unique de la combinaison fipronil et perméthrine offre une excellente efficacité acaricide à la fois contre $I$. ricinus et $R$. sanguineus pour au moins 4 semaines.

\section{Background}

Tick infestations represent an important problem for dogs and their owners. Ixodes ricinus and Rhipicephalus sanguineus are two of the most common tick species infesting dogs in Europe. They are known to also infest humans, and are vectors for several important canine and human diseases' agents [1,2]. Adequate control measures to prevent and treat infestations in dogs against these species are therefore very important for the health and well-being of dogs.

Ixodes ricinus is widely distributed throughout Europe [3] and is the most common tick species in northwestern Europe [4]. The distribution of this tick species has been expanding in both range and period of activity, possibly due to climate change [5-7]. In dogs, I. ricinus is the vector of Anaplasma phagocytophilum, Borrelia burgdorferi sensu lato and tick borne encephalitis (TBE) virus [3]. In humans, it can serve as the vector for $B$. burgdorferi s.l., Babesia divergens, Babesia microti and also TBE virus [1]. Rhipicephalus sanguineus has a worldwide distribution and is the most commonly encountered tick species (or complex of species) infesting dogs [8]. It is the vector for the most common tickborne pathogens in dogs, which include Ehrlichia spp., Rickettsia spp., Babesia spp. and Hepatozoon canis. $[3,8-10]$, as well as for the pathogens of spotted fever and ehrlichiosis in humans.

Adequate control of tick infestations on dogs is important for both the health of the dog and for preventing pet dogs from carrying and serving as a source of ticks in the home environment of their owners. Various formulations of topical- and collar-based treatments have been employed as a strategy to combat tick infestations in dogs [8,11-13]. Fipronil is one of the most widely used insecticides/acaricides to control fleas and ticks on both dogs and cats [13]. Pyrethroids have also been used as insecticides and acaricides with repellent activity on dogs [14-18], production animals [19] and humans [20,21]. Frontline Tri-Act ${ }^{\oplus} /$ Frontect $^{\odot}$ is a novel combination of $6.76 \% \mathrm{w} / \mathrm{v}$ fipronil and $50.48 \% \mathrm{w} / \mathrm{v}$ permethrin that has been developed as a monthly topical solution for dogs to provide broad spectrum ectoparasite control. Studies were conducted to confirm the acaricidal efficacy of this combination against I. ricinus and $R$. sanguineus ticks.

\section{Methods}

The studies were designed in accordance with the "World Association for the Advancement of Veterinary Parasitology (W.A.A.V.P.) guidelines for evaluating the efficacy of parasiticides for the treatment, prevention and control of flea and tick infestation on dogs and cats" [22] and were conducted in accordance with Good Clinical Practices (GCP) as described in the International Cooperation on Harmonisation of Technical Requirements for Registration of Veterinary Medicinal Products (VICH guideline 9).

\section{Animals}

None of the dogs had been exposed to ectoparasiticides for the three months preceding the study. Prior to allocation for each study, 20 healthy Beagle dogs (in Study A) and 14 mixed breed dogs (in Study B) were infested with approximately $50+/-5$ unfed adult $R$. sanguineus (approx. equal sex ratio) and the ticks were removed and counted from 
each dog after $48 \mathrm{~h}$. The two male and two female dogs with the lowest tick counts were dropped from Study A and the two dogs (regardless of sex) with the lowest tick counts were dropped from Study B. The remaining dogs were ranked within sex by descending tick counts and assigned to blocks of two dogs each. Within blocks, each dog was randomly allocated to the treated and untreated groups. The dogs were managed with due regard for their well-being in accordance with Merial, South African and Irish Institutional Animal Care and Use Committee requirements. The dogs were housed individually. A veterinary examination performed prior to the start of each study ensured that all dogs were healthy and suitable for inclusion, and the dogs were observed daily for any health changes throughout the study.

\section{Treatment}

Dogs in Group 1 of Study A and B served as untreated controls. Dogs in Group 2 of both studies were treated once on Day 0 with a topical formulation containing $6.76 \%(\mathrm{w} / \mathrm{v})$ fipronil and $50.48 \%(\mathrm{w} / \mathrm{v})$ permethrin with a total volume corresponding to the appropriately sized pipette based upon body weight such that dogs weighing less than or equal to $10 \mathrm{~kg}$ received $1.0 \mathrm{~mL}$, dogs weighing greater than 10 but less than $20 \mathrm{~kg}$ received $2.0 \mathrm{~mL}$, and dogs weighing greater than 20 but less than $40 \mathrm{~kg}$ received $4.0 \mathrm{~mL}$. The total volume of the product was divided into two approximately equal fractions and placed on the skin on the midline of the neck. One fraction was applied between the base of the skull and the shoulder blades and the other was applied at the front of the shoulder blades. All of the animals were observed hourly for any adverse reaction for $4 \mathrm{~h}$ following the treatment of the last animal.

\section{Ticks}

The ticks used in the studies were unfed adult $I$. ricinus ticks (50 females with 4-5 added males for each challenge) and unfed adult $R$. sanguineus ticks (approx. equal sex ratio) that were not known to be resistant to any ectoparasiticide. The ticks originated from European tick populations, now bred under experimental conditions. The $I$. ricinus ticks originated from natural populations from the United Kingdom, Slovakia, and Ireland. The $R$. sanguineus ticks used in Study A originated from natural populations from Oxford, UK, and for Study B the ticks originated from field collections in France.

\section{Tick infestation and counting}

Dogs in both studies were infested prior to treatment (Day -2 in Study A, Day -1 in Study B) and post treatment on Days 7, 14, 21 and 28 with 50 unfed adult R. sanguineus (approx. equal sex ratio). In Study A each dog was also infested with 50 unfed adult female $I$. ricinus ticks (with at least an additional 10 male $I$. ricinus ticks to stimulate female attachment) at the same time points.

Live ticks on the dogs were removed and counted on Days 2, 9, 16, 23 and 30 (48 h after treatment or infestation). Ixodes ricinus and $R$. sanguineus ticks were counted and recorded separately. Only female I. ricinus were counted while for $R$. sanguineus, both females and males were counted.

For tick infestations and counting in Study A, dogs were anesthetized with intramuscular injections of ketamine (Narketan ${ }^{\oplus}$, Vetoquinol; approx. $10.0 \mathrm{mg} / \mathrm{kg}$ ) and xylazine (Chanazine $^{\oplus}$, Chanelle; approx. $2.0 \mathrm{mg} / \mathrm{kg}$ ). In Study B, dogs were sedated with medetomidine (Domitor ${ }^{\ominus}$, Pfizer; $0.06 \mathrm{mg} / \mathrm{kg}$ ) for tick infestations only.

\section{Data analysis}

For each tick species, total counts of live ticks were transformed to the natural logarithm of (counts +1$)$ for calculation of geometric means (GM) by treatment group at each time point. As described in the WAAVP guidelines, the use of geometric means allow to describe a central tendancy whereas arithmetic means maintains the same weight to extreme data. Percent efficacy of the treated group compared to the control group was calculated at every post-treatment time point using the formula $100 \times[(\mathrm{C}-\mathrm{T}) / \mathrm{C}]$, where $\mathrm{C}$ is the GM for the control group and $\mathrm{T}$ is the GM for the treated group.

In Study A the treated group was compared to the control group at every post-treatment time using the Friedman rank test with blocks defined as the allocation blocks. The testing was two-sided and used a significance level of $5 \%$. All analyses were performed using $\mathrm{SAS}^{\bullet}$ Version 9.1.3. In Study B the groups were compared by a non-parametric analysis using the MannWhitney test. SAS ${ }^{\ominus}$ Version 9.3 TS Level $1 \mathrm{M} 2$ was used for the statistical analysis.

\section{Results}

No adverse reactions to treatment were observed in any dog in either study, including during the $4 \mathrm{~h}$ after treatment.

A summary of the tick counts and efficacy results are shown in Table 1 (Study A) and Table 2 (Study B).

The percent efficacy of the treated group for $R$. sanguineus was 100\%, 100\%, 100\%, 100\% and 96.7\% in Study A, and $94.4 \%, 100 \%, 100 \%, 98.7 \%$ and $98.0 \%$ in Study B, for counts performed on Days 2, 9, 16, 23 and 30, respectively. There was a significant difference of the geometric mean number of live ticks between the treated and control groups in both studies at each time point ( $p=0.005$ for every day in Study A, and $p<0.005$ for every day in Study B).

For $I$. ricinus the percent efficacy of the treated group was $100 \%, 100 \%, 100 \%, 100 \%$ and $99.2 \%$ for counts performed on Days 2, 9, 16, 23 and 30, respectively. There was a significant difference of geometric mean number of live 
Table 1 Efficacy of a new combination of fipronil and permethrin against Rhipicephalus sanguineus and Ixodes ricinus (Study A)

\begin{tabular}{lllll}
\hline $\begin{array}{l}\text { Tick } \\
\text { species }\end{array}$ & $\begin{array}{l}\text { Study } \\
\text { day }\end{array}$ & \begin{tabular}{l} 
Geometric mean of live ticks \\
\cline { 3 - 4 }
\end{tabular} & $\begin{array}{l}\text { Untreated control } \\
\text { dogs }(\mathbf{n}=\mathbf{8})\end{array}$ & $\begin{array}{l}\text { Treated } \\
\text { dogs }(\mathbf{n}=\mathbf{8})\end{array}$ \\
\hline R. sanguineus & 2 & 31.8 & 0.0 & $100.0^{*}$ \\
R. sanguineus & 9 & 24.8 & 0.0 & $100.0^{*}$ \\
R. sanguineus & 16 & 27.8 & 0.0 & $100.0^{*}$ \\
R. sanguineus & 23 & 22.8 & 0.0 & $100.0^{*}$ \\
R. sanguineus & 30 & 24.7 & 0.7 & $96.7^{*}$ \\
I. ricinus & 2 & 36.7 & 0.0 & $100^{*}$ \\
I. ricinus & 9 & 32.5 & 0.0 & $100.0^{*}$ \\
I. ricinus & 16 & 30.7 & 0.0 & $100.0^{*}$ \\
I. ricinus & 23 & 31.6 & 0.0 & $100.0^{*}$ \\
I. ricinus & 30 & 33.3 & 0.3 & $99.2^{*}$ \\
\hline
\end{tabular}

*Significant difference between the tick population means of the treated and control groups $(p=0.005)$.

ticks between the treated and control groups at each time point ( $p=0.005$ for every day).

In addition, the majority of dogs remained free of live ticks in the treated groups. All of the dogs treated with the tested spot-on were not infested with ticks at the counts performed for I. ricinus on Days 2, 9, 16 and 23; on Day 30, 6 out of 8 treated dogs did not harbour tick (data not shown). In Study A, no ticks were found on all of the treated dogs at the counts performed for R. sanguineus on Days 2, 9, 16 and 23; on Day 30, only 2 of 8 dogs were found to be infested with ticks. In Study B all of the dogs in the treated group were not infested with ticks on Days 9 and 16. On Days 23 and 30, 4 out of 6 treated dogs were tick free (data not shown).

\section{Discussion}

The results of the studies presented here demonstrate that a single topical treatment with the combination of fipronil and permethrin provides excellent efficacy against both $I$. ricinus and $R$. sanguineus. In each counting time points in both studies, the mean infestation rate in the control group

Table 2 Efficacy of a new combination of fipronil and permethrin against Rhipicephalus sanguineus (Study B)

\begin{tabular}{llll}
\hline Study day & \multicolumn{2}{l}{ Geometric mean of live ticks } & \\
\cline { 2 - 3 } & $\begin{array}{l}\text { Untreated control } \\
\text { dogs }(\mathbf{n}=6)\end{array}$ & $\begin{array}{l}\text { Treated dogs } \\
(\mathbf{n}=6)\end{array}$ & Efficacy (\%) \\
\hline 2 & 35.9 & 2.0 & $94.4^{*}$ \\
9 & 27.0 & 0.0 & $100.0^{*}$ \\
16 & 33.1 & 0.0 & $100.0^{*}$ \\
23 & 38.7 & 0.5 & $98.7^{*}$ \\
30 & 32.0 & 0.6 & $98.0^{*}$ \\
\hline
\end{tabular}

*Significant difference between the tick population means of the treated and control groups $(p \leq 0.005)$. for both $I$. ricinus and $R$. sanguineus was very good. The average number of I. ricinus per dog in the control group ranged from 30.7 to 36.7 ticks per dog, while for $R$. sanguineus the average tick number per dog ranged from 22.8 to 31.8 in Study A and from 27.0 to 38.7 in Study B. In comparison, there were no live ticks found on the dogs treated with the combination of fipronil and permethrin in either study for the Day 9 and Day 16 counts and only a very low number of ticks found on Days 2, 23, and 30 (Tables 1 and 2). These results are in the range to what has already been published with other acaricidal spot-on formulations like Frontline ${ }^{\circ}$ Combo or Advantix ${ }^{\circ}[8,12,13,16-18]$ and exceed the European regulatory threshold of more than $90 \%$ of efficacy counted at $48 \mathrm{~h}$ to get a claim.

Frontline Tri-Act $^{\circ} /$ Frontect $^{\circ}$ has also been shown to have repellent and parasiticidal efficacy against Dermacentor ticks [23], fleas [24,25], mosquitoes and plebotomine sandflies [26,27], indicating that the combination of fipronil and permethrin can be an important component in the reduction of the risk of transmission of most canine vector-borne diseases.

\section{Conclusions}

In conclusion, a single topical administration of a combination of fipronil and permethrin provides excellent acaricidal efficacy against both $I$. ricinus and $R$. sanguineus for at least 4 weeks. The product is safe and can also be used to reduce the risk of transmission of tickborne pathogens in dogs.

\section{Competing interests}

The work reported herein was funded by Merial Limited. All authors were employees or contractors of Merial.

\section{Authors' contributions}

PD, STC, BG, MS and FB participated in the design of the studies and protocols, and PD, BG, JF and FB carried out the studies. STC compiled and analysed the data. All authors read and approved the final manuscript.

\section{Acknowledgements}

The authors are sincerely grateful to all monitors, investigators and the staff of the study locations (Ireland and South Africa) either linked to the authors or serving as independent CROs who took part in the studies and ensured that high GCP standards were adhered to.

Frontline Tri-Act $^{\oplus}$ and Frontect ${ }^{\oplus}$ are registered trademarks of Merial in France and pending registration in other countries. All other marks are the property of their respective owners.

This document is provided for scientific purposes only. Any reference to a brand or trademark herein is for informational purposes only and is not intended for a commercial purpose or to dilute the rights of the respective owner(s) of the brand(s) or trademark(s).

\section{Author details}

${ }^{1}$ Merial S.A.S., 29 Av. Tony Garnier, 69007 Lyon, France. ${ }^{2}$ Merial Limited, 3239 Satellite Blvd., Duluth, GA 30096, USA. ${ }^{3}$ Charles River Laboratories Preclinical Services Ireland Ltd., Carrentrila, Ballina, Co. Mayo, Ireland. ${ }^{4}$ ClinVet

International (Pty) Ltd, PO Box 11186, 9321 Universitas, Bloemfontein, South Africa.

Received: 20 January 2015 Accepted: 21 January 2015

Published online: 27 January 2015 


\section{References}

1. Dantas-Torres F, Chomel BB, Otranto D. Ticks and tick-borne diseases: a One Health perspective. Trends Parasitol. 2012;28:437-46.

2. Wilhelmsson $P$, Lindblom $P$, Fryland $L$, Nyman $D$, Jaenson TG, Forsberg $P$, et al. Ixodes ricinus ticks removed from humans in Northern Europe: seasonal pattern of infestation, attachment sites and duration of feeding. Parasit Vectors. 2013;6:362.

3. Chomel B. Tick-borne infections in dogs-an emerging infectious threat Vet Parasitol. 2011;179:294-301.

4. Claerebout E, Losson B, Cochez C, Casaert S, Dalemans AC, De Cat A, et al. Ticks and associated pathogens collected from dogs and cats in Belgium. Parasit Vectors. 2013:6:183.

5. Beugnet F, Chalvet-Monfray K. Impact of climate change in the epidemiology of vector-borne diseases in domestic carnivores. Comp Immunol Microbiol Infect Dis. 2013;36:559-66.

6. Gray JS, Dautel H, Estrada-Pena A, Kahl O, Lindgren E. Effects of climate change on ticks and tick-borne diseases in europe. Interdiscip Perspect Infect Dis. 2009;2009:593232.

7. Dantas-Torres F, Otranto D. Seasonal dynamics of Ixodes ricinus on ground level and higher vegetation in a preserved wooded area in southern Europe. Vet Parasitol. 2013;192:253-8.

8. Brianti E, Pennisi MG, Brucato G, Risitano AL, Gaglio G, Lombardo G, et al Efficacy of the fipronil 10\% + (S)-methoprene 9\% combination against Rhipicephalus sanguineus in naturally infested dogs: speed of kill, persistent efficacy on immature and adult stages and effect of water. Vet Parasitol. 2010:170:96-103.

9. Jongejan F, Uilenberg G. The global importance of ticks. Parasitology. 2004;129(Suppl):S3-14

10. Shaw SE, Day MJ, Birtles RJ, Breitschwerdt EB. Tick-borne infectious diseases of dogs. Trends Parasitol. 2001;17:74-80.

11. Beugnet F, Franc M. Results of a European multicentric field efficacy study of fipronil-(S) methoprene combination on flea infestation of dogs and cats during 2009 summer. Parasite. 2010;17:337-42.

12. Bonneau S, Gupta S, Cadiergues MC. Comparative efficacy of two fipronil spot-on formulations against experimental tick infestations (Ixodes ricinus) in dogs. Parasitol Res. 2010;107:735-9.

13. Kuzner J, Turk S, Grace S, Soni-Gupta J, Fourie JJ, Marchiondo AA, et al Confirmation of the efficacy of a novel fipronil spot-on for the treatment and control of fleas, ticks and chewing lice on dogs. Vet Parasitol. 2013;193:245-51.

14. Brianti E, Falsone L, Napoli E, Prudente C, Gaglio G, Giannetto S. Efficacy of a combination of $10 \%$ imidacloprid and $4.5 \%$ flumethrin (Seresto(R)) in slow release collars to control ticks and fleas in highly infested dog communities. Parasit Vectors. 2013;6:210.

15. Dantas-Torres F, Capelli G, Giannelli A, Ramos RA, Lia RP, Cantacessi C, et al. Efficacy of an imidacloprid/flumethrin collar against fleas, ticks and tick-borne pathogens in dogs. Parasit Vectors. 2013:6:245.

16. Doyle V, Beugnet F, Carithers D. Comparative efficacy of the combination fipronil-(S)-methoprene and the combination permethrin-imidacloprid against Dermacentor reticulatus, the European dog tick, applied topically to dogs. Vet Ther. 2005;6:303-10

17. Endris RG, Everett R, Cunningham J, Katz TL, Thompson K. Efficacy of two $65 \%$ permethrin spot-on formulations against canine infestations of Ctenocephalides felis and Rhipicephalus sanguineus. Vet Ther. 2002;3:326-33.

18. Endris RG, Hair JA, Katz TL, Zobre E, Pennington RG, Meyer JA. Efficacy of three dose volumes of topically applied 65\% permethrin against Ctenocephalides felis and Rhipicephalus sanguineus on dogs weighing $30 \mathrm{~kg}$ or more Vet Ther 2002:3:435-40.

19. Ndeledje N, Bouyer J, Stachurski F, Grimaud P, Belem AM, Molele Mbaindingatoloum F, et al. Treating cattle to protect people? Impact of footbath insecticide treatment on tsetse density in Chad. PLoS One. 2013;8:e67580

20. Bissinger BW, Apperson CS, Watson DW, Arellano C, Sonenshine DE, Roe RM. Novel field assays and the comparative repellency of BioUD((R)), DEET and permethrin against Amblyomma americanum. Med Vet Entomol. 2011:25:217-26.

21. Miller NJ, Rainone EE, Dyer MC, Gonzalez ML, Mather TN. Tick bite protection with permethrin-treated summer-weight clothing. J Med Entomol. 2011:48:327-33.

22. Marchiondo AA, Holdsworth PA, Fourie LJ, Rugg D, Kellmann K, Snyder DE, et al. World Association for the Advancement of Veterinary Parasitology
(W.A.A.V.P.) second edition: guidelines for evaluating the efficacy of parasiticides for the treatment, prevention and control of flea and tick infestations on dogs and cats. Vet Parasitol. 2013;194:84-97.

23. Dumont $P$, Fourie JJ, Soll MD, Beugnet F. Acaricidal and repellent efficacy of new combination of fipronil and permethrin against the main vector of canine babesiosis in Europe: Dermacentor reticulatus ticks. Parasit Vectors (in press).

24. Fankhauser B, Dumont P, Halos L, Hunter IIIJS, Kunkle B, Everett WR, et al. Efficacy of a new combination of fipronil and permethrin against Ctenocephalides felis flea infestation in dogs. Parasit Vectors (in press).

25. Beugnet F, Soll MD, Bouhsira E, Franc M. Sustained speed of kill and "repellence" of a new combination of fipronil and permethrin against Ctenocephalides canis flea infestation in dogs. Parasit Vectors (in press).

26. Fankhauser B, Dumont $P$, Hunter IIIJS, McCall JW, Kaufmann C, Mathis A, et al. Repellent efficacy of a new combination of fipronil and permethrin against several mosquitoes species (Aedes sp., Culex sp.). Parasit Vectors (in press).

27. Dumont $P$, Fankhauser $B$, Bouhsira $E$, Lienard $E$, Jacquiet $P$, Beugnet $F$, et al. Repellent efficacy of a new combination of fipronil and permethrin against the main vector of canine leishmaniosis in Europe (Phlebotomus perniciosus). Parasit Vectors (in press).

\section{Submit your next manuscript to BioMed Central and take full advantage of:}

- Convenient online submission

- Thorough peer review

- No space constraints or color figure charges

- Immediate publication on acceptance

- Inclusion in PubMed, CAS, Scopus and Google Scholar

- Research which is freely available for redistribution 